\title{
On the Use of Pulsed UV or Visible Light Activated Gas Sensing of Reducing and Oxidising Species with $\mathrm{WO}_{3}$ and $W_{2}$ Nanomaterials
}

\author{
Ernesto González $^{1}{ }^{(\mathbb{D}}$, Juan Casanova-Chafer ${ }^{1}{ }^{(D)}$, Aanchal Alagh ${ }^{1}$, Alfonso Romero ${ }^{1}\left(\mathbb{D}\right.$, Xavier Vilanova $^{1, *(\mathbb{D})}$, \\ Selene Acosta ${ }^{2} \mathbb{D}$, Damien Cossement ${ }^{3}$, Carla Bittencourt ${ }^{2} \mathbb{D}$ and Eduard Llobet ${ }^{1}$ (D)
}

1 Electronic Engineering, Uiversitat Rovira i Virgili, 43007 Tarragona, Spain; ernesto.gonzalez@urv.cat (E.G.); juan.casanova@urv.cat (J.C.-C.); alagh.aanchal@urv.cat (A.A.); alfonso.romero@urv.cat (A.R.); eduard.llobet@urv.cat (E.L.)

2 Chimie des Interactions Plasma e Surface (ChIPS), Research Institute for Materials Science and Engineering, Université de Mons, 7000 Mons, Belgium; selene.acostamorales@umons.ac.be (S.A.); carla.bittencourt@umons.ac.be (C.B.)

3 Materia Nova, Parc Initialis, 7000 Mons, Belgium; damien.cossement@materianova.be

* Correspondence: xavier.vilanova@urv.cat; Tel.: +34-977-558-502

\section{check for} updates

Citation: González, E.; CasanovaChafer, J.; Alagh, A.; Romero, A.; Vilanova, X.; Acosta, S.; Cossement, D.; Bittencourt, C.; Llobet, E. On the Use of Pulsed UV or Visible Light Activated Gas Sensing of Reducing and Oxidising Species with $\mathrm{WO}_{3}$ and $\mathrm{WS}_{2}$ Nanomaterials. Sensors 2021, 21, 3736. https://doi.org/10.3390/ s21113736

Academic Editor: Giovanni Neri

Received: 10 April 2021

Accepted: 25 May 2021

Published: 27 May 2021

Publisher's Note: MDPI stays neutral with regard to jurisdictional claims in published maps and institutional affiliations.

Copyright: (c) 2021 by the authors. Licensee MDPI, Basel, Switzerland. This article is an open access article distributed under the terms and conditions of the Creative Commons Attribution (CC BY) license (https:// creativecommons.org/licenses/by/ $4.0 /)$.
Abstract: This paper presents a methodology to quantify oxidizing and reducing gases using n-type and p-type chemiresistive sensors, respectively. Low temperature sensor heating with pulsed UV or visible light modulation is used together with the application of the fast Fourier transform (FFT) to extract sensor response features. These features are further processed via principal component analysis (PCA) and principal component regression (PCR) for achieving gas discrimination and building concentration prediction models with $\mathrm{R}^{2}$ values up to $98 \%$ and RMSE values as low as $5 \%$ for the total gas concentration range studied. UV and visible light were used to study the influence of the light wavelength in the prediction model performance. We demonstrate that n-type and p-type sensors need to be used together for achieving good quantification of oxidizing and reducing species, respectively, since the semiconductor type defines the prediction model's effectiveness towards an oxidizing or reducing gas. The presented method reduces considerably the total time needed to quantify the gas concentration compared with the results obtained in a previous work. The use of visible light LEDs for performing pulsed light modulation enhances system performance and considerably reduces cost in comparison to previously reported UV light-based approaches.

Keywords: gas sensing; pulsed light modulation; FFT; PCA; PCR; $\mathrm{NO}_{2} ; \mathrm{NH}_{3}$

\section{Introduction}

Over the past few decades, many research efforts have been directed towards indoor and outdoor air quality monitoring. The direct relation between environmental pollutants and human health has promoted the research on this topic. According to the World Health Organization, about 7 million people die every year caused by diseases related to air pollution [1]. Exposure to gases present in the atmosphere due to industrial activity, such as $\mathrm{NH}_{3}$ and $\mathrm{NO}_{2}$ can cause skin and eye damage and affect the respiratory and cardiovascular systems [2-4].

Some different operating principles such as electrochemical [5,6], optical [7,8], or chemiresistive have been used for gas sensing [9-12] related to air quality monitoring. One of the most studied approaches has been the use of metal oxides (MOX) chemiresistors due to their high sensitivity and the relatively simple associated driving and readout electronics, which confers them enormous versatility for being employed in a wide range of different applications, such as toxic and combustible gas detection, biosensing, environmental safety, and food quality control [13-20]. The operating principle of MOX sensors relies on surface redox reactions. Target gas molecules interact with oxygen species trapped at 
the sensor surface, thus, changing the electronic charge distribution in the sensing material, which eventually results in a resistance change [21-24].

Typically, MOX sensors have been operated highly above room temperature, at a few hundred degrees centigrade to enable surface reactions and achieve high sensitivity and baseline recovery. Heating supposes an important power consumption issue, especially for non-MEMS sensors, making them not suitable for portable or low-power applications [25-27]. Nevertheless, some different techniques have been employed during the last years to solve the problem generated by power consumption issues. The use of thermal modulation, UV-light irradiation at room temperature, and UV light activation combined with mild temperature heating, instead of working with just thermal activation at high temperatures have gained prominence $[16,26,28-33]$. The photoconductivity effect caused by the UV light irradiation creates electron-hole pairs, which increase the density of carrier charges along the semiconductor, making an acceleration of the absorption/desorption mechanism [34]. The use of UV light irradiation not only makes the sensor response of MOXs higher at low or even at room temperature but also shortens the time needed to reach the steady-state and to recover the sensor baseline [34,35]. Light enhanced gas sensing has been also applied on perovskite and metal transition dichalcogenides [36-39]. Although the light activation (constant light irradiation throughout all the measurement time or during the baseline recovery time) has been widely used for enhancing the sensing performance using light sources with a wavelength from the UV to the visible spectrum, only very few works present the study of a pulsed light mechanism. The use of UV light modulation with MOXs through a pulsed light activation mechanism has been employed to quantify gas concentration. This method is carried out by using the resistance changes induced by the pulsed light, which creates a ripple on the sensor resistance curve $[31,40,41]$. The information extracted from the resistance transients is used to establish a relationship with the target gas concentration. In addition, this method shortens response time and the humidity effect on sensing performance is reduced as well $[40,41]$. This methodology was also employed in the development of a portable system for the detection of $\mathrm{NO}_{2}$ at $\mathrm{ppb}$ levels [42].

On the other hand, some researchers have studied the quantification of target gas concentration and different gas discrimination using mathematical and statistical methods. Multivariate methods such as PCA, PCR, and machine learning have been employed for this purpose [43-47]. The combined use of electronic noses that employ arrays of sensors with the aforementioned methods has been applied to discriminate and quantify gases (e.g., $\mathrm{NO}_{2}$, ammonia, ethanol, acetone) [43,47-53]. Most of these works implement the mentioned data analysis by using sensor response feature vectors as input for the multivariate and machine learning approaches. Nevertheless, a few researchers have reported the use of the fast Fourier transform (FFT) components obtained from the sensor resistance transient as inputs for the data analysis strategies $[54,55]$. Employing this last approach, we have developed a methodology for quantifying $\mathrm{NO}_{2}$ using UV light modulation and FFT analysis of the sensor response signals from n-type metal oxide sensors [56]. However, pulsed UV light, n-type metal oxide sensors were found to lack accuracy at quantifying reducing species such as ammonia.

In this paper, we refine further and generalize our approach for quantifying both oxidizing and reducing species using light-pulsed chemiresistive sensors. For generalizing the methods, n-type $\left(\mathrm{WO}_{3}\right.$ and $\left.\mathrm{SrTiO}_{3} @ \mathrm{WO}_{3}\right)$ and p-type $\left(\mathrm{WS}_{2}\right)$ sensors were synthesized and measured under combined low temperature and pulsed UV or visible light modulation. The inclusion of a p-type chemiresistor enabled the reliable quantification of reducing species, which had not been achieved before. The development of PCR models and their validation process for quantifying $\mathrm{NO}_{2}$ and $\mathrm{NH}_{3}$ concentration using FFT components from the analysis of the response transients is discussed. PCA is used to identify when sensors are exposed to $\mathrm{NO}_{2}$ or $\mathrm{NH}_{3}$. The refinements implemented enable reducing the time needed to successfully quantify the target gas concentration and improve model 
accuracy at estimating gas concentrations. These new findings expand the opportunities of using pulsed light chemisensing in different real applications.

\section{Experimental Set-Up}

\subsection{Sensor Fabrication}

\subsubsection{Strontium Titanate Loaded Tungsten Trioxide Sensors}

Tungsten trioxide nanoneedles (NNs) functionalized with strontium titanate nanoparticles were grown using a one-step process of aerosol assisted chemical vapor deposition (AACVD) which is a widely used technique for synthesizing MOX nano and microstructures [57]. Materials were grown on top of a commercial alumina substrate from Ceram Tech $\mathrm{GmBH}$, with screen-printed, interdigitated platinum electrodes (300 $\mu \mathrm{m}$ gap) on the front side and an $8 \Omega$ screen-printed heater on the backside. In a mixture of $24 \mathrm{~mL}$ of acetone (CAS: 67-64-1) and $9 \mathrm{~mL}$ of methanol (CAS: 67-56-1), $50 \mathrm{mg}$ of tungsten hexacarbonyl (W(CO) 6 ) (purity 97\%, CAS: 14040-11-0) were dissolved. Following this, $5 \mathrm{mg}$ of strontium titanate nanopowder (CAS: 12060-59-2) were dispersed inside the solution using an ultrasonic bath. Nitrogen $\left(\mathrm{N}_{2}\right)$ was used as a carrier gas to transport the aerosols generated by means of an ultrasonic humidifier at a flow of about $800 \mathrm{sccm}$. The total transport of the aerosols and the deposition process took about $40 \mathrm{~min}$. The deposition chamber temperature was kept at $400{ }^{\circ} \mathrm{C}$ during all the deposition processes and then naturally cooled down to room temperature. After the one-step growth in the AACVD, an annealing process was performed at $500{ }^{\circ} \mathrm{C}$ for $2 \mathrm{~h}$ in a Carbolite CWF 1200 muffle furnace, to fully oxidize the $\mathrm{WO}_{3}$ and remove the residual carbon from the precursor.

\subsubsection{Tungsten Trioxide $\left(\mathrm{WO}_{3}\right)$}

Pure $\mathrm{WO}_{3}$ sensors were fabricated using the same procedure and equipment described for the case of $\mathrm{SrTiO}_{3} @ \mathrm{WO}_{3}$ sensors, but without including the strontium titanate nanopowders. In this case, $50 \mathrm{mg}$ of tungsten hexacarbonyl were dissolved in a mixture of $15 \mathrm{~mL}$ of acetone and $5 \mathrm{~mL}$ of methanol, and the rest of the conditions were kept equal to those in the previously described synthesis.

\subsubsection{Tungsten Disulphide $\left(\mathrm{WS}_{2}\right)$}

Multi-layered nanosheets of $\mathrm{WS}_{2}$ were synthesized in two steps. First, $\mathrm{WO}_{3} \mathrm{NNs}$ were grown using AACVD as described above. During the second step of synthesis, the asgrown $\mathrm{WO}_{3}$ nanomaterial was sulfurized to form $\mathrm{WS}_{2}$ in a quartz tube furnace using an atmospheric pressure chemical vapor deposition technique (CVD) under hydrogen-free conditions. Before the sulfurization process, the quartz tube was flushed with $0.5 \mathrm{~L} / \mathrm{min}$ of argon gas to remove any oxygen present in the reactor. Two ceramic boats containing an equal amount of sulfur (S) powder (>99.95\%, Sigma Aldrich, CAS: 7704-34-9) were placed at different temperature zones of the deposition furnace. Furthermore, a smaller semi-sealed quartz tube loaded with substrate containing nanoneedles of $\mathrm{WO}_{3}$ with a boat carrying $S$ precursor was introduced inside the larger quartz tube, such that both the substrate and the $\mathrm{S}$ boat are positioned at the center of the deposition furnace. Afterward, a second boat carrying an equal amount of $S$ powder was introduced inside the upstream of the bigger quartz tube. Then the furnace was heated from room temperature to $900{ }^{\circ} \mathrm{C}$ with a heating rate of $40^{\circ} \mathrm{C} / \mathrm{min}$ to remove the contaminants, such as water or residual organics to obtain the nucleation of $\mathrm{WS}_{2}$. The growth of $\mathrm{WS}_{2}$ was kept at $900{ }^{\circ} \mathrm{C}$ for $30 \mathrm{~min}$ under a constant flow of argon. After the growth phase, the furnace was cooled naturally to room temperature.

\subsection{Morphological Characterization Systems}

The different sensors were characterized via Field Emission Scanning Electron Microscope (FESEM), Energy-dispersive X-ray Spectroscopy (EDX), Raman Spectroscopy, X-ray Diffraction (XRD), X-ray Photoelectron Spectroscopy (XPS), and Time-of-Flight Secondary Ions Mass Spectrometry (ToF-SIMS). The FESEM-FIB Scios 2 from FEI Company was used 
to obtain images from the sensor surface to analyze nanostructure growth and distribution. Sample characterization was performed at high-vacuum, and the electron acceleration voltage was established between 2 and $5 \mathrm{kV}$. EDX incorporated in the FESEM-FIB Scios 2 was used to check the chemical composition of the sensors.

An FT-IR Raman spectrometer from Renishaw and the DM2500 confocal microscope from Leica Microsystems were used to perform the Raman spectroscopy analysis. Laser sources with a wavelength of 514, 633, and $785 \mathrm{~nm}$ were used. The laser beam power was set at $0.1 \%$.

XRD measurements were made using a Siemens D5000 diffractometer (Bragg-Brentano parafocusing geometry and vertical $\theta-\theta$ goniometer) fitted with a curved graphite diffractedbeam monochromator, incident and diffracted -beam Soller slits, a $0.06^{\circ}$ receiving slit, and scintillation counter as a detector. The angular $2 \theta$ diffraction range was between 5 and $70^{\circ}$. The data were collected with an angular step of $0.05^{\circ}$ at 3 s per step and sample rotation. Cuk $\alpha$ radiation was obtained from a copper $\mathrm{X}$-ray tube operated at $40 \mathrm{kV}$ and $30 \mathrm{~mA}$.

For XPS experiments a VERSAPROBE PHI5000 spectrometer from Physical Electronics, equipped with a monochromatic AlK X-Ray was used. The energy resolution was $0.6 \mathrm{eV}$. A dual beam charge neutralization composed of an electron gun $(\sim 1 \mathrm{eV})$ and the Argon Ion gun $(\leq 10 \mathrm{eV})$ was used for compensation of charge built up on the sample surface during the measurements. All binding energies were calibrated to the $\mathrm{C} 1$ s peak at $284.6 \mathrm{eV}$. The CASA XPS software was used for spectra analysis.

The ToF-SIMS experiments were conducted on a TOF-SIMS IV instrument from IONTOF GmbH (Münster, Germany). Prior to the analysis, the sample surface $(600 \times 600 \mu \mathrm{m})$ was sputter cleaned using $\mathrm{O}_{2}$ ions accelerated at $1 \mathrm{kV}$, for $120 \mathrm{~s}$. For recording the $\mathrm{m} / \mathrm{z}$ spectra, a pulsed $25 \mathrm{kV} \mathrm{Bi1+} \mathrm{ion} \mathrm{beam} \mathrm{rastered} \mathrm{during} 300 \mathrm{~s}$ over an area of $100 \times 100 \mu \mathrm{m}^{2}$, was used. The total ion fluence was kept under 1012 ions per $\mathrm{cm}^{2}$ in order to assure static conditions. The secondary ions were extracted at a $2 \mathrm{kV}$ acceleration voltage. Positive spectra were calibrated to the $\mathrm{H}+, \mathrm{C}+, \mathrm{CH}+, \mathrm{CH}_{2}+, \mathrm{CH}_{3}+, \mathrm{C}_{2} \mathrm{H}_{3}+$, and $\mathrm{C}_{2} \mathrm{H}_{5}+$ peaks.

\subsection{Gas Measuring System Description}

Measurements were made inside a Teflon chamber with an inner volume of about $21 \mathrm{~cm}^{3}$. The chamber is totally isolated from the ambient light and has the capacity to hold up to four sensors at the same time, which allows the use of the three types of sensors synthesized at the same time. LEDs are inserted in the chamber top through two air-tight connection joints, staying at about $7.5 \mathrm{~mm}$ from the sensor surface, which allows homogeneous irradiation. Connectors in the back side of the chamber allow control of the sensors operating temperature and measure the resistance of the sensing layers. Sensor resistance is measured and recorded every $1 \mathrm{~s}$ by using a Keysight 34972A LXI Data Acquisition/Switch Unit controlled with BenchLink Data Logger 3 from Agilent Technologies.

Gas concentrations established to test the sensors were set by mean of a mass-flow controller system (EL-FLOW®) from Bronkhorst, using Flow View and Flow Plot software from the same company. $\mathrm{NO}_{2}$ and $\mathrm{NH}_{3}$ flows coming from calibrated cylinders with $1 \mathrm{ppb}$ and 100 ppm respectively (balanced in synthetic air) were mixed in adequate proportions with a synthetic air flow coming from a zero-grade air cylinder. The total flow across the chamber was kept at $100 \mathrm{~mL} / \mathrm{min}$ during all the measurements.

To build and validate the models presented in this work, sensors were exposed to $\mathrm{NO}_{2}$ concentrations of 250,500, and $750 \mathrm{ppb}$, and $\mathrm{NH}_{3}$ concentrations of 25, 50, and $75 \mathrm{ppm}$. Gas concentrations were selected to be under the exposure limits established by the Occupational Safety and Health Administration (OSHA) permissible exposure limit (PEL), and the National Institute for Occupational Safety and Health (NIOSH) recommended exposure limit (REL), from the United States. Every gas cycle made was composed of 3 different $\mathrm{NO}_{2}$ or $\mathrm{NH}_{3}$ concentrations, using 15 min of gas exposure and then $1 \mathrm{~h}$ of baseline recovery under synthetic air. Figure S1 in the SI shows a schema of the gas measurement system used. 


\subsection{Light Pulse Generation}

UV and visible light modulations were carried out using LEDs with an emission wavelength of 365 (MT3650W3-UV from Marktech Optoelectronics) nm and $410 \mathrm{~nm}$ (OSV5HA5A32A from Optosupply), respectively. An electronic circuit was designed and implemented to control the forward current of the LEDs. To power up the control circuit and set the activation and deactivation periods of the LEDs, an Arduino Mega 2560 from Arduino was used. Digital outputs and timers from the Arduino were used for this purpose.

\subsection{Data Analysis Process Description}

In order to generate a quick pathway to quantify both oxidizing and reducing gases concentration some mathematical and computational tools such as fast Fourier transform (FFT), PCA, and PCR have been used. The data analysis process implemented to quantify the gas concentrations was carried out using Matlab R2020a.

In contrast to traditional methods to characterize chemiresistive gas sensors and quantify gas concentrations, where the steady-state response of the sensor resistance and then the full baseline recovery is needed, the methodology presented in this work requires just a few minutes to accurately quantify the studied gas concentration. Figure 1 depicts the flow diagram from the data analysis process.

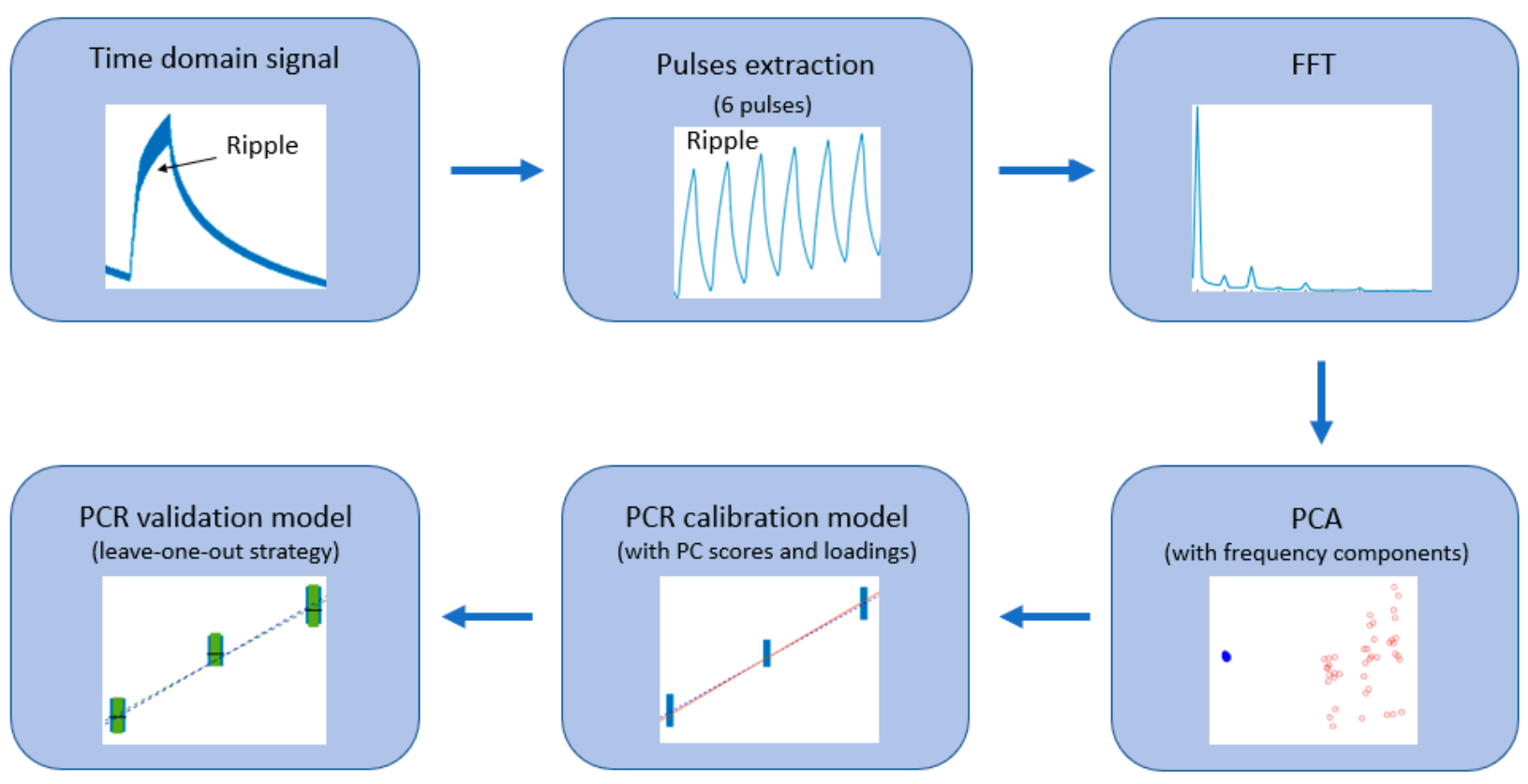

Figure 1. Data analysis process flow diagram.

Similar to the methodology presented in [56], a frequency domain analysis is performed to the sensor signal, which shows a ripple, due to the exposure to a visible or UV light modulation, on top of the resistance changes related to the sensor interaction with gases. During the semi-period where the modulating light is off, just the reaction of the sensing material with the target gas takes place at the sensor surface, while in the semi-period where the light is on, photons from the light create electron-hole pairs which participate in the current conduction, and in addition, they promote the desorption of surface adsorbed species, thus, modulating the resistance from the sensing material. Tungsten trioxide is an n-type MOX, which has a bandgap of about $2.7 \mathrm{eV} \mathrm{[58].} \mathrm{Strontium} \mathrm{titanate} \mathrm{is} \mathrm{an} \mathrm{n-type}$ perovskite oxide with a bandgap of about $3.2 \mathrm{eV}$ [59]. Tungsten disulphide is a p-type semiconductor that has a bandgap of about $1.3 \mathrm{eV}[60,61]$. The photon energies of the used purple (visible) and UV LEDs are $3.02 \mathrm{eV}$ and $3.40 \mathrm{eV}$, respectively. Regarding the $\mathrm{SrTiO}_{3} @ \mathrm{WO}_{3}$ sensor, an equilibrium between the Fermi levels takes place due to the forma- 
tion of a heterojunction at the interface. Thus, even though the creation of electron-hole pairs is not promoted in the $\mathrm{SrTiO}_{3}$ by visible light due to the photon energy be lower than its bandgap, it acts as a catalyst to promote the separation of the electron-hole pairs, which provides redox reaction sites [59].

\section{Models based on FFT Components}

Based on the results obtained in [56] the pulsed light ON/OFF period was set to $20 \mathrm{~s}$ to have a higher number of light pulses within the analyzed time. In order to shorten the number of samples used in the analysis, a period of $2 \mathrm{~min}$ from the time domain signal was selected to perform the FFT (shown in Figure 2a). Thus, having a sampling rate of $1 \mathrm{~Hz}$, vectors used to perform the FFT have 120 values, which is equivalent to six light ON/OFF pulses. Due to the time needed to establish a homogeneous gas concentration inside the chamber, the first 6 min of each gas pulse is not used in the analysis. Hence, the 7th and 8th minutes (counted from the gas cycle start) of each gas pulse are used to create the vectors employed to perform de FFT analysis. After carrying out the FFT analysis, vector size is halved. Hence, the frequency components vector obtained (related to each gas cycle) has half of the size with respect to the time domain signal vector. However, not all the frequency components are used to build the training matrix used to develop the PCR calibration models. FFT vectors are manipulated to use just the components which give relevant information from the sensor signal. As Figure $2 \mathrm{~b}$ shows, the switching frequency of the pulsed light $(0.05 \mathrm{~Hz}$ for an ON/OFF period of $20 \mathrm{~s})$ and its even order harmonics appear in the frequency spectrum. Hence, to reduce the number of components used to build the training matrix and eliminate low-intensity frequency components, which can be affected by noise, just frequency components with a relevant magnitude are taken. The training matrix is built by concatenating the new vectors related to each concentration. Rows (observations) represent different concentrations, and columns (variables) are each of the frequency components used. The training matrix built with the frequency components is used to perform the PCA and the principal components (PC) obtained in this process are used to perform the PCR calibration models. In addition, it is possible to build the training matrix using frequency components related to more than one sensor or including observations from different gases. Hence, the scores and loadings plots obtained from the PCA are useful to identify different gases and distinguish the contribution of each PC to the discrimination performance. The accuracy of both n-type $\left(\mathrm{WO}_{3}\right.$ and $\left.\mathrm{SrTiO}_{3} @ \mathrm{WO}_{3}\right)$ and p-type $\left(\mathrm{WS}_{2}\right)$ sensors to quantify oxidizing $\left(\mathrm{NO}_{2}\right)$ and reducing $\left(\mathrm{NH}_{3}\right)$ gases was tested by performing calibration models and these were cross-validated, with the combined use of low operating temperature $\left(50^{\circ} \mathrm{C}\right)$ and light modulation. In addition, the effect of applying light modulation, exciting the sensor surface with LEDs having wavelengths in the ultraviolet and visible spectrum was evaluated. Results from the prediction model accuracies are evaluated through the R-squared $\left(R^{2}\right)$ and Root Mean Square Error (RMSE) values.

Cross-validation methods are used to do the validation process and evaluate the model's accuracy to predict the target gas concentration. Hence, a leave-one-out strategy is applied cyclically. First, the data related to one of the cycles of 3 concentrations is left out of the training matrix, and the PCR is performed with the rest of the data. Then, the beta values obtained from the PCR are used with the new data (left out data) to identify the gas concentration and validate the methods. Once the strategy is applied to all the data, the validation model is obtained by concatenating each set of data identified. 

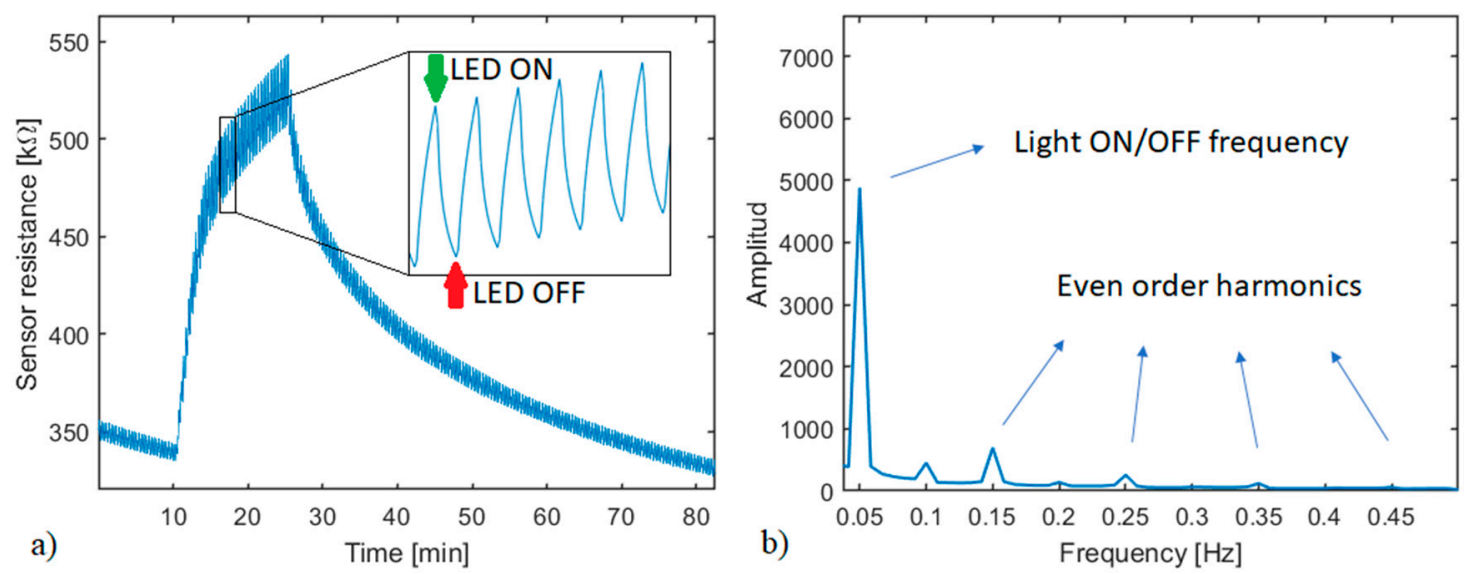

Figure 2. (a) Time-domain data extraction from the sensor response to a gas pulse to perform the FFT, 2 min (6 light pulses) of signal are used. (b) Frequency domain obtained after applying the FFT. The light switching frequency and its even order harmonics are specified.

\section{Results and Discussion}

\subsection{Morphological Characterization}

Figure 3 depicts typical FESEM images from pure $\mathrm{WO}_{3} \mathrm{NNs}$ at 2 different magnification values. The EDX spectrum (see Figure S2a in the SI) shows that the $\mathrm{WO}_{3} \mathrm{NNs}$ are composed of tungsten and oxygen, being the sample free of any contaminant. Raman spectroscopy was also employed. From the Raman spectrum (shown in Figure 4), the position and intensity of the bands at $807,717,325$, and $274 \mathrm{~cm}^{-1}$ are typical from the monoclinic phase of $\mathrm{WO}_{3}$ [62-64]. XRD analysis results (see Figure S3a in the SI), also confirm the presence of the monoclinic phase of $\mathrm{WO}_{3}$.

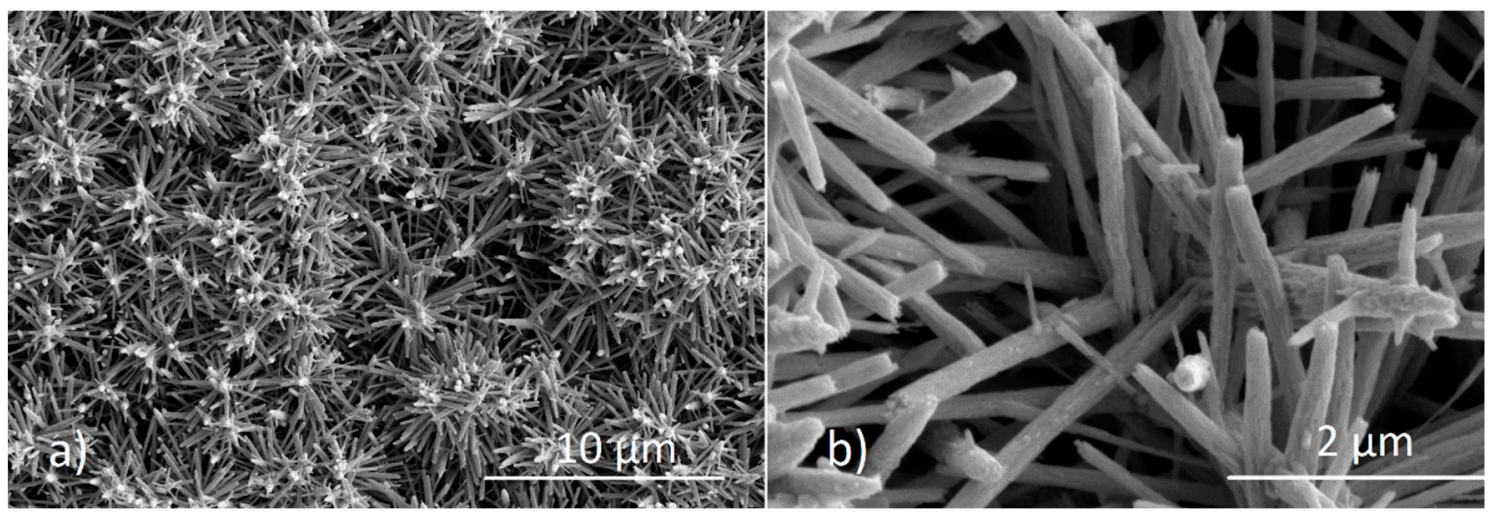

Figure 3. Tungsten trioxide nanoneedles, (a) 6500× of magnification and (b) 37,400× of magnification. Working with an electron beam acceleration voltage of $5 \mathrm{kV}$.

Figure 5 shows typical FESEM images where the morphology of the nanoneedles for strontium titanate loaded $\mathrm{WO}_{3}$ is revealed. The tips of loaded NWs present a granular morphology. EDX analysis does not show the presence of Sr or Ti in loaded samples. In fact, the EDX spectrum for strontium titanate loaded $\mathrm{WO}_{3}$ is identical to the one shown in Figure S2a in the SI for the pristine $\mathrm{WO}_{3}$ material, so it can be concluded that the granular morphology at the tips of NWs corresponds also to $\mathrm{WO}_{3}$. Raman spectroscopy and XRD were also performed and neither the spectrogram nor the diffractogram show peaks that indicate the presence of $\mathrm{SrTiO}_{3}$. After these analyses, it was possible only to confirm the presence of $\mathrm{WO}_{3}$ in its monoclinic phase. XPS and ToF-SIMS were also used to evaluate the surface composition. The XPS spectrum recorded on the $\mathrm{SrTiO}_{3} @ \mathrm{WO}_{3}$ sample is shown in Figure S4 in the SI, the peaks generated by photoelectrons emitted from $\mathrm{W}, \mathrm{O}$, and $\mathrm{C}$ 
atoms are clearly recognized. The relative amount of each observed element was O $24 \%$ at., $\mathrm{W} 70 \%$ at., and C 6\% at., the detailed analysis of the $\mathrm{W} 4 \mathrm{f}$ indicates that the oxidation state of the $\mathrm{W}$ atoms is +6 . XPS did not detect the presence of $\mathrm{SrTiO}_{3}$ at the sample surface. Finally, ToF-SIMS was considered for investigating the presence of strontium titanate in loaded $\mathrm{WO}_{3}$ samples, due to the higher sensitivity of this technique to detect trace elements in comparison to any of the previously used ones. The ToF-SIMS spectra (see Figure S5 in SI) confirm the presence of Sr and Ti. It is therefore concluded that loaded samples contain strontium titanate, on the surface of $\mathrm{WO}_{3}$ but at low concentrations (i.e., below the detection threshold of XRD and XPS).

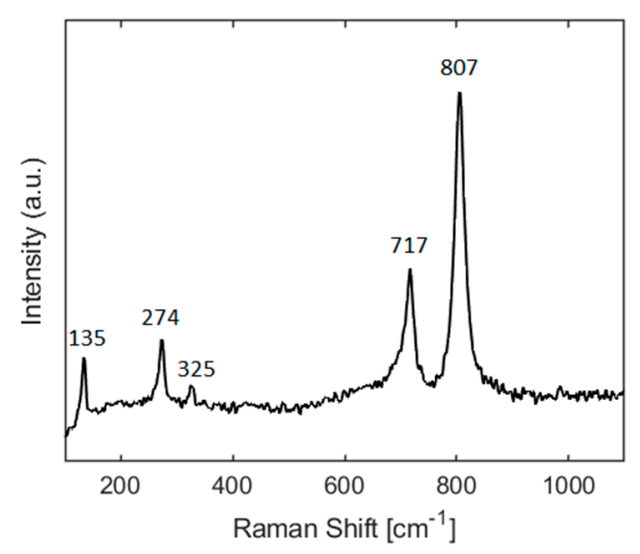

Figure 4. Raman spectrum from the $\mathrm{WO}_{3}$ sensor measured using $633 \mathrm{~nm}$ excitation.
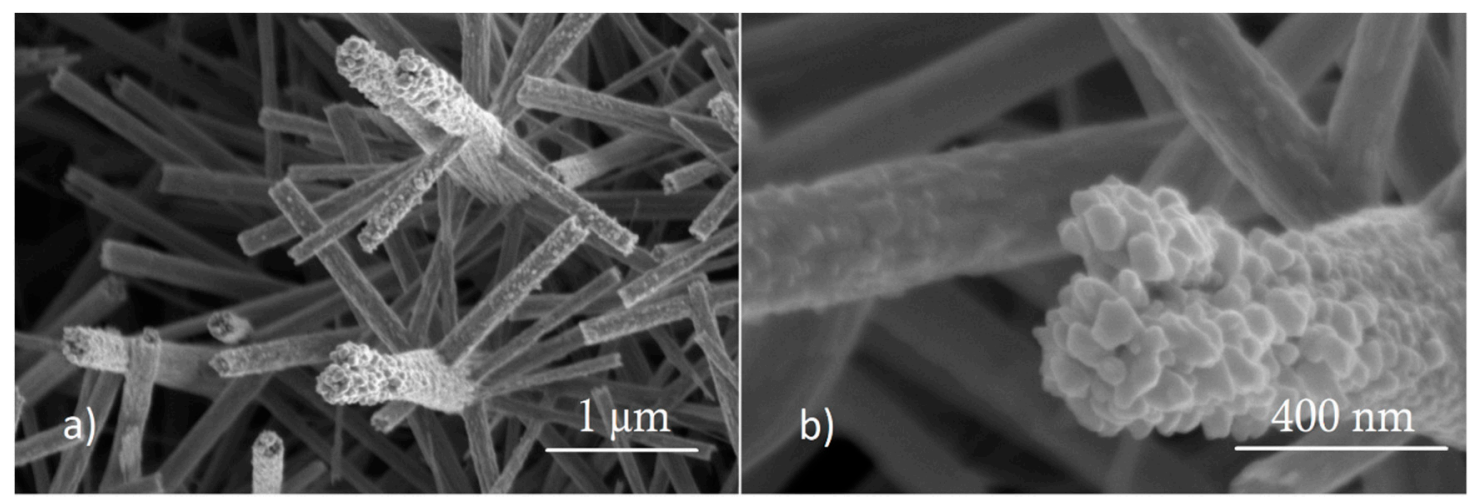

Figure 5. $\mathrm{SrTiO}_{3} @ \mathrm{WO}_{3}$ sensor surface, (a) 41,000× magnification with an electron beam acceleration voltage of $2 \mathrm{kV}$, and (b) $150,000 \times$ magnification and an electron beam acceleration voltage of $5 \mathrm{kV}$.

The as-grown nanofilms of $\mathrm{WS}_{2}$ were strongly adherent to the substrate with dark black color. The results obtained revealed that the $\mathrm{WO}_{3} \mathrm{NNs}$ morphology changed completely to form nanoflakes of $\mathrm{WS}_{2}$, which can be well-identified in Figure 6. Furthermore, it can be seen that these nanoflakes are assembled in a 3D topology and appear as nanoflowers.

From the EDX spectrum shown in Figure S2b in the SI, it is confirmed that the composition of the as-grown nanoflakes of $\mathrm{WS}_{2}$ consists of sulfur and tungsten. No oxygen peak is identified in the EDX spectrum, which apparently confirms the development of a high-yield $\mathrm{WS}_{2}$ phase, free from oxide content. Also, the grown material was characterized using Raman spectroscopy to confirm its purity. From the Raman spectrum (shown in Figure 7), 2 important Raman peaks, characteristic of $2 \mathrm{H}-\mathrm{WS}_{2}$ were observed at 348 and $414 \mathrm{~cm}^{-1}$. Additionally, two broad peaks with very low intensity were also detected at 701 and $804 \mathrm{~cm}^{-1}$, indicating the presence of some $\mathrm{WO}_{3}$ impurities that could be present in the bulk of the grown material [65]. 

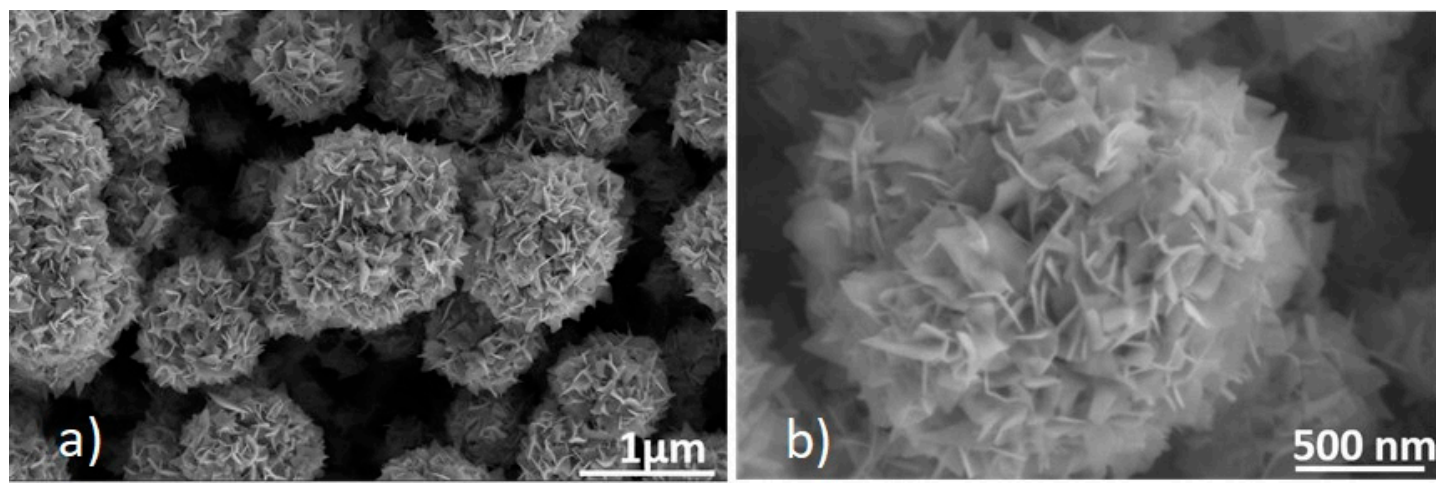

Figure 6. FESEM image depicting nanoflakes of $\mathrm{WS}_{2}$ assembled to form nanoflowers. Magnification of (a) $25,000 \times$ and $(\mathbf{b})$ $65,000 \times$. The electron beam acceleration voltage was set at $5 \mathrm{kV}$.

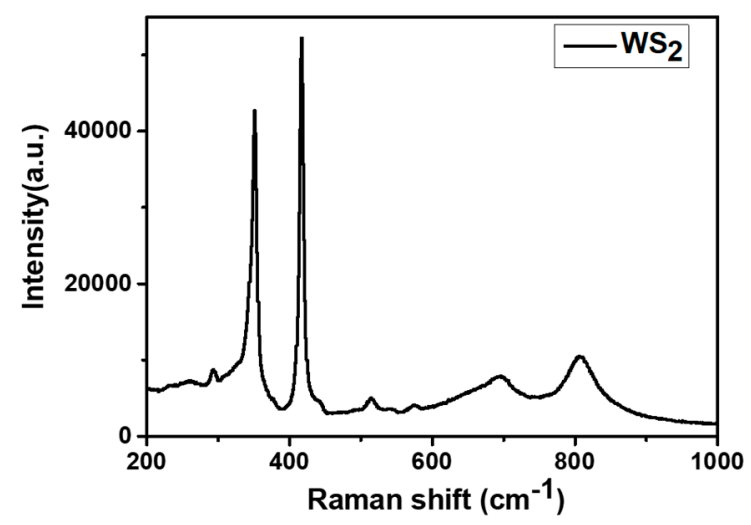

Figure 7. Raman spectrum from the $\mathrm{WS}_{2}$ sensor.

XPS was used to evaluate the formation of W-S bonds. The peaks shown in Figure S6a, corresponding to the $S 2 p_{1 / 2}$ and $S 2 p_{3 / 2}$ orbital of divalent sulfide ions, are observed at 163.3 and $162.1 \mathrm{eV}$. The $\mathrm{W}$ peaks shown in Figure S6b located at 38.3, 34.7, and $32.5 \mathrm{eV}$ correspond to $W 5 p_{3 / 2}, W 4 f_{5 / 2}$, and $W 4 f_{7 / 2}$, respectively. The energy positions of these peaks indicate a $W$ valence of +4 , which is in accordance with the previous reports. The other doublet with components at $\mathrm{W} 4 \mathrm{f}_{5 / 2}$, and $\mathrm{W} 4 \mathrm{f}_{7 / 2}$ respectively at 30.8 and $35.8 \mathrm{eV}$ indicates the presence of $\mathrm{W}-\mathrm{O}$ in $\mathrm{WO}_{3}$. The Raman spectroscopy, EDX, and XRD results (Figures S2b and S3b) did not indicate the presence of tungsten oxide. As XPS is sensitive to the near surface region, while the other techniques probe much deeper below the surface, the comparison of the results of these different techniques indicate that the oxide is mainly located near the surface.

In summary, the sulfurization process conducted on $\mathrm{WO}_{3} \mathrm{NNs}$ yields a $3 \mathrm{D}$ assembly of $\mathrm{WS}_{2}$ nanoflakes with a small amount of $\mathrm{WO}_{3}$ impurities, as revealed by Raman and XPS.

\subsection{Gas Sensing Characterization}

\subsubsection{Standard Operation}

After the morphological and compositional characterization of the synthesized materials, sensors were tested for gas sensing. In the first stage, the sensors were activated by heating their active films and without light modulation. Using the procedures described before, the gas sensing properties were investigated at the operating temperatures of 50 , 100 , and $150^{\circ} \mathrm{C}$. When the n-type sensors $\left(\mathrm{WO}_{3}\right.$ and $\left.\mathrm{SrTiO}_{3} @ \mathrm{WO}_{3}\right)$ were exposed to an oxidizing gas $\left(\mathrm{NO}_{2}\right)$ and the p-type sensor $\left(\mathrm{WS}_{2}\right)$ to a reducing species $\left(\mathrm{NH}_{3}\right)$, their response monotonically increased as the temperature was raised. Thus, the highest responses were obtained when the operating temperature was set at $150{ }^{\circ} \mathrm{C}$. Figure S7 in the supporting information summarizes these results. In contrast, $\mathrm{n}$-type sensors presented a poor response 
reproducibility towards $\mathrm{NH}_{3}$ for all the operating temperatures tested. Similarly, the p-type sensor presented also reproducibility issues when exposed to $\mathrm{NO}_{2}$. In conclusion, for the range of operating temperatures studied, $\mathrm{WO}_{3}$ and $\mathrm{SrTiO}_{3} @ \mathrm{WO}_{3}$ sensors are more suited for detecting nitrogen dioxide, while $\mathrm{WS}_{2}$ is more suited for detecting ammonia.

\subsubsection{Pulsed Light Modulation}

The input of each frequency component to the gas identification process was evaluated through biplots performed with the scores and loadings from the PCA. The analysis of the frequency components selection for performing the target gas identification is presented in Figures S8 and S9 in the SI. Results from this analysis show that using just the ON/OFF frequency related to the $\mathrm{SrTiO}_{3} @ \mathrm{WO}_{3}$ sensor and its first even order harmonic contains enough information for discriminating between the two species considered. This is true for visible and UV light excitation. Furthermore, using these two frequency components it is possible to separate observations related to different $\mathrm{NO}_{2}$ concentrations in the scores plot. In the same way, frequency components (ON/OFF and its first even order harmonic) extracted from the $\mathrm{WS}_{2}$ sensor allow separating $\mathrm{NH}_{3}$ concentrations in different groups in the scores plot. Thus, all the training matrices used to obtain the PCA scores plots presented in Figure 8 were built using just the light switching frequency and its first even order harmonic. If the $\mathrm{WO}_{3}$ pristine sensor is used to perform the same analysis, the PCA scores plot allows to discriminate between $\mathrm{NH}_{3}$ and $\mathrm{NO}_{2}$ observations, but when the sensor works under UV light modulation the ability to separate each gas concentration worsens.

Figure 8a,b show the PCA scores plot obtained from a training matrix built using observations from both $\mathrm{NO}_{2}$ and $\mathrm{NH}_{3}$ and frequency components related to the $\mathrm{SrTiO}_{3} @ \mathrm{WO}_{3}$ sensor, under visible and UV light modulation, respectively. It is clear that $\mathrm{NH}_{3}$ and $\mathrm{NO}_{2}$ observations can be separated into different clusters according to the PC1. In a supposed real application, this would allow the identification of the target gas for using the proper model to quantify the gas concentration. Different $\mathrm{NO}_{2}$ concentrations can be also identified in clusters separated according to PC1.

Figure $8 \mathrm{c}, \mathrm{d}$ depict the PCA scores plots obtained when the training matrix is made using just $\mathrm{NO}_{2}$ observations and frequency components from the $\mathrm{SrTiO}_{3} @ \mathrm{WO}_{3}$ sensor, working under visible and UV light modulation, respectively. In both cases, the different gas concentrations can be grouped and separated according to the PC1, which allows to perform a qualitative identification of the concentration. Figure $8 \mathrm{e}$ and $\mathrm{f}$ show the PCA scores plot obtained from a training matrix built with just observations of $\mathrm{NH}_{3}$ and frequency components from the $\mathrm{WS}_{2}$ sensor when it works under visible and UV light modulation, respectively. In this case, when the $\mathrm{WS}_{2}$ sensor works under visible light it is possible to identify different clusters for each concentration organized according to the PC1, although higher concentration clusters are close together. When the $\mathrm{WS}_{2}$ sensor is operated under UV light modulation, the clusters corresponding to different concentrations can be separated as well, although some of the 50 and $75 \mathrm{ppm}$ observations are overlapped. In this case, the cluster orientation is diagonal due to a different distribution of the variance explained by each principal component with respect to when the sensor is operated under visible light modulation.

From these results, it is deduced that under light pulse modulation n-type sensors are useful for quantifying oxidizing species $\left(\mathrm{NO}_{2}\right)$ and p-type sensors are suitable for quantifying reducing species $\left(\mathrm{NH}_{3}\right)$. PCR models built for predicting concentration are discussed below.

According to the results obtained with the principal component analysis, the PCR calibration models, and cross-validation results presented in Figures 9 and 10 were obtained using scores and loadings data from 1st and 2nd principal components obtained from the PCA developed using just two frequency components (light switching frequency and its first even order harmonic). These two PCs explain over $99 \%$ of the data variance. PCR models related to the $\mathrm{WO}_{3}$ pristine sensors are presented in Figure S10 in the SI. 

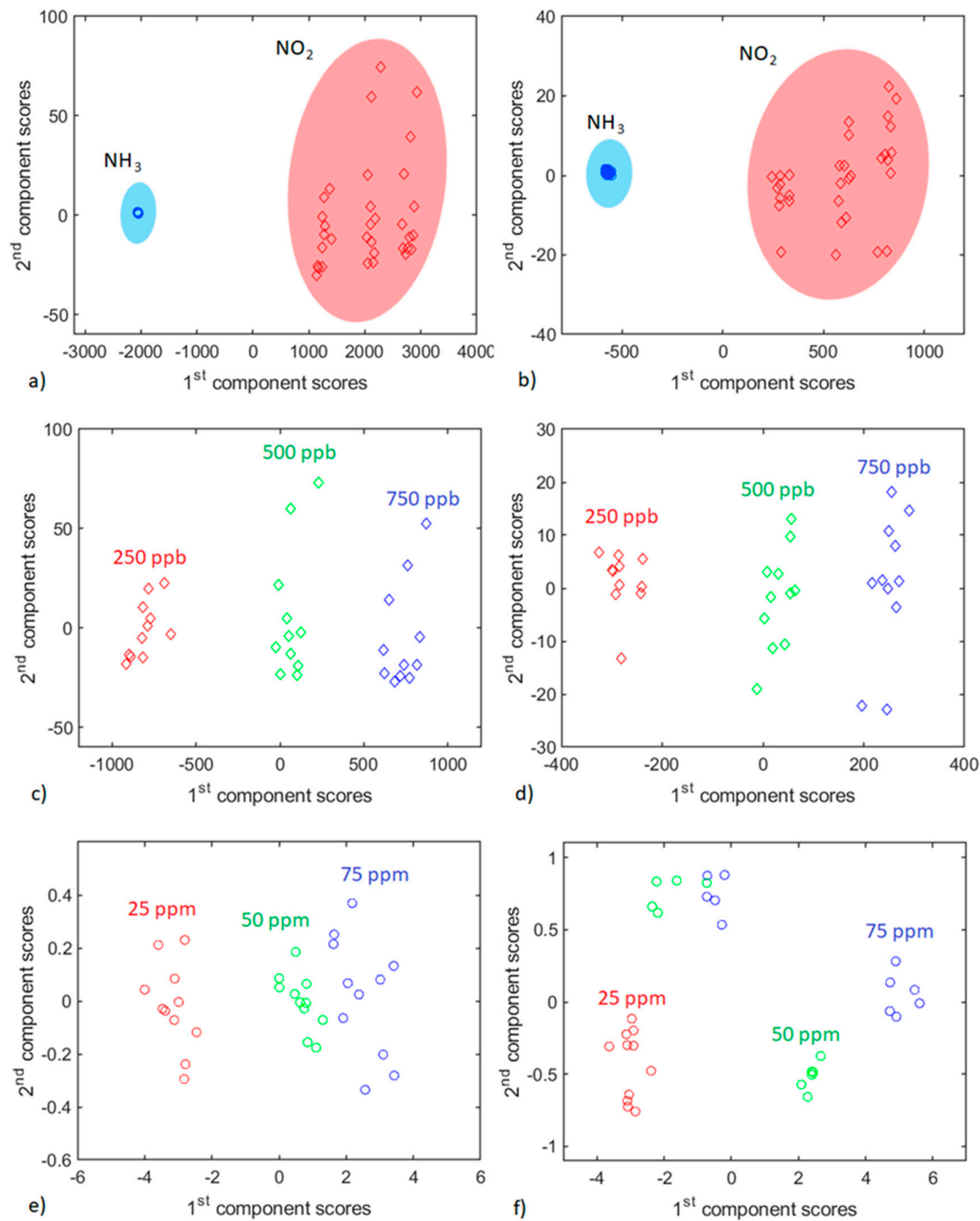

Figure 8. PCA scores plot for (a,c,e) visible light modulation and $(\mathbf{b}, \mathbf{d}, \mathbf{f})$ UV light modulation using two frequency components from $\mathrm{WS}_{2}$ or $\mathrm{SrTiO}_{3} @ \mathrm{WO}_{3}$ sensors. PCA from a and b were performed using observations of $\mathrm{NO}_{2}$ and $\mathrm{NH}_{3}$ to construct the training matrix and frequency components from the $\mathrm{SrTiO}_{3} @ \mathrm{WO}_{3}$ sensor, while c, $\mathrm{d}$, and e, f belong to PCA developed with observations of just $\mathrm{NO}_{2}$ and just $\mathrm{NH}_{3}$, and frequency components from the $\mathrm{SrTiO}_{3} @ \mathrm{WO}_{3}$ sensor and the $\mathrm{WS}_{2}$ sensor, respectively. In the figure, circles represent $\mathrm{NH}_{3}$ observations and diamonds represent $\mathrm{NO}_{2}$ observations. The first two PCs explain over $99 \%$ of data variance.

Figure 9a,b illustrates the $\mathrm{WS}_{2}$ and $\mathrm{SrTiO}_{3} @ \mathrm{WO}_{3}$ sensors results for $\mathrm{NH}_{3}$ and $\mathrm{NO}_{2}$, respectively, under UV light modulation. $\mathrm{WS}_{2}$ sensor model presents an $\mathrm{R}^{2}$ value of about 0.90 and its RMSE value is about $13 \%$ for the total measured concentration range. On the other hand, the $\mathrm{SrTiO}_{3} @ \mathrm{WO}_{3}$ sensor model presents an $\mathrm{R}^{2}$ value near 0.97 and its RMSE value represents just $7.44 \%$ of the total measured concentration variation. Results obtained make the models suitable for quantifying and predicting the target gas concentrations. 
Figure 10 shows how, for the two sensor types, $R^{2}$ values are higher than 0.92 and RMSE values represent near or less than $10 \%$ for the concentration measured range. Results obtained when the sensors are working under visible light modulation are better than those when UV light is used. The model obtained with the $\mathrm{SrTiO}_{3} @ \mathrm{WO}_{3}$ sensor reaches almost 0.98 of $R^{2}$ and has an RMSE value that represents just about $5 \%$ of the total measured concentration range. The performance of all sensors when quantifying gas concentrations is better under visible light modulation than under UV modulation. From the results obtained it may be deduced that the $\mathrm{SrTiO}_{3}$ loading gives more stability to sensor response and makes this hybrid more suitable for being used to predict $\mathrm{NO}_{2}$ concentrations than using pure $\mathrm{WO}_{3}$ sensors.
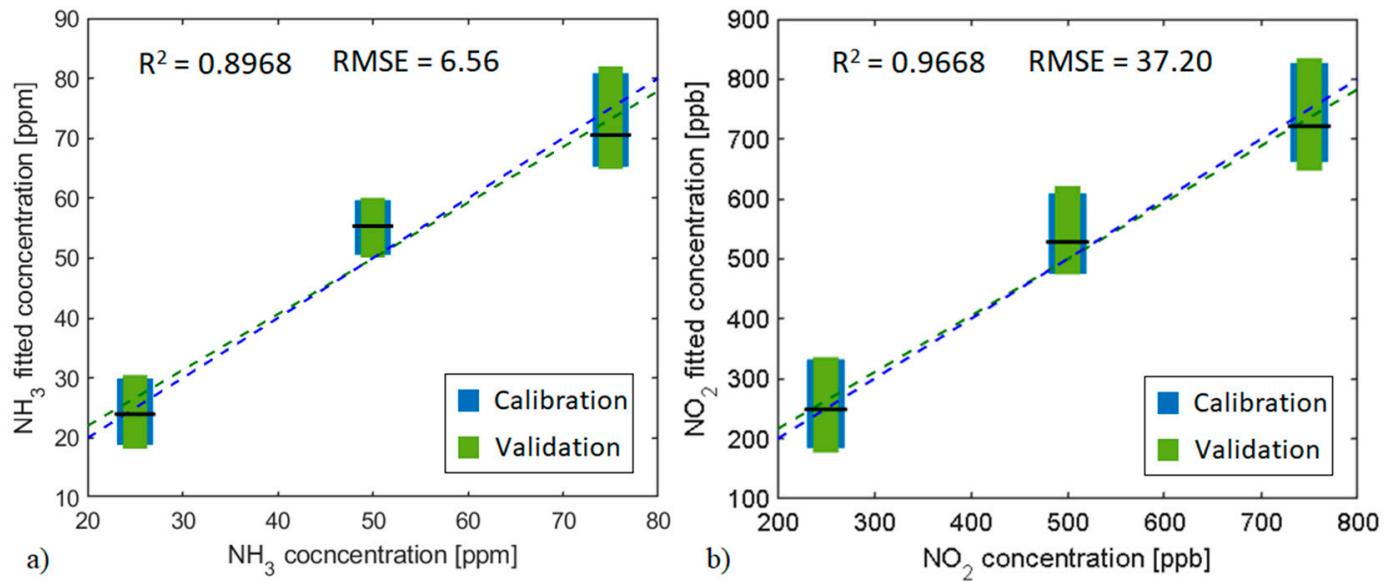

Figure 9. PCR calibration model and cross-validation for the (a) $\mathrm{WS}_{2}$ sensor towards $\mathrm{NH}_{3}$ concentrations and (b) $\mathrm{SrTiO}_{3} @ \mathrm{WO}_{3}$ sensor towards $\mathrm{NO}_{2}$ concentrations. The operating temperature was $50{ }^{\circ} \mathrm{C}$ and the light modulation was done with UV LEDs. Blue boxes represent the calibration model dispersion for each concentration and green boxes the validation dispersion. The horizontal black line represents the mean value for the validation process. The validation linear fit is shown with the green dashed line, and the blue dashed line represents a unitary slope line. R-squared and RMSE values belong to the calibration model.
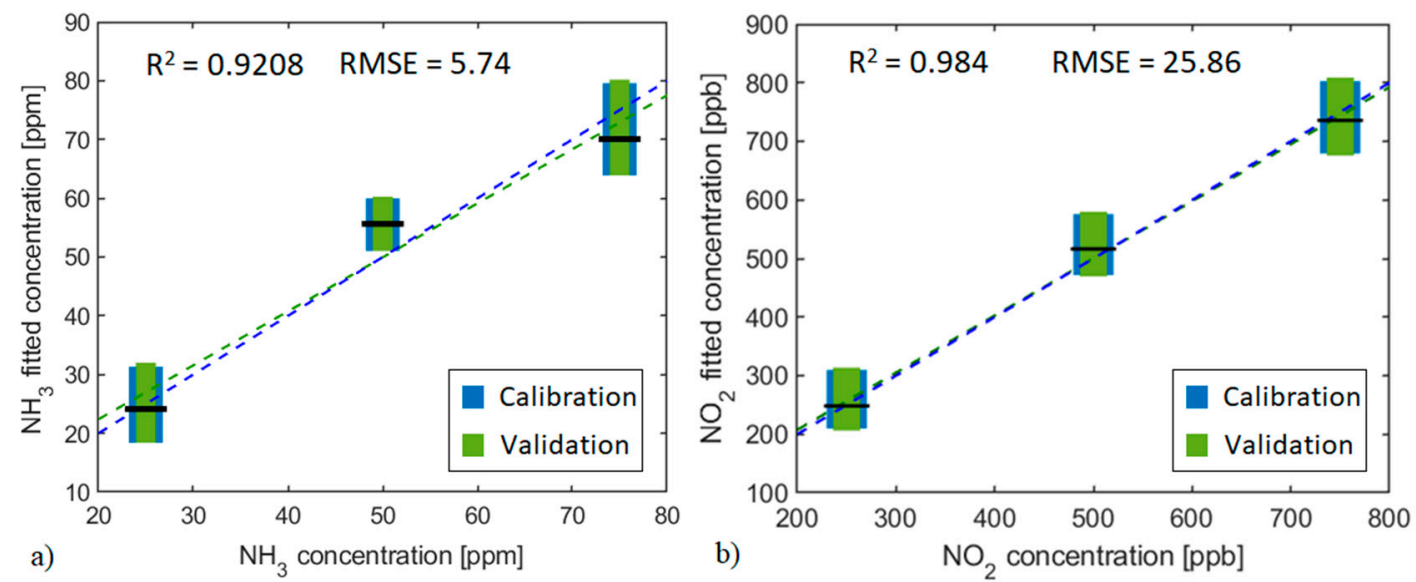

Figure 10. PCR calibration model and cross-validation for the (a) $\mathrm{WS}_{2}$ sensor towards $\mathrm{NH}_{3}$ concentrations and (b) $\mathrm{SrTiO}_{3} @ \mathrm{WO}_{3}$ sensor towards $\mathrm{NO}_{2}$ concentrations. The operating temperature was $50{ }^{\circ} \mathrm{C}$ and the light modulation was done with purple visible light LEDs. Blue boxes represent the calibration model dispersion for each concentration and green boxes the validation dispersion. The horizontal black line represents the mean value for the validation process. The validation linear fit is shown with the green dashed line, and the blue dashed line represents a unitary slope line. R-squared and RMSE values belong to the calibration model. 
To further support these conclusions, PCR models were also built and validated for n-type sensors to quantify ammonia and for p-type sensors to quantify nitrogen dioxide (see Figure S11 in the SI) achieving bad performance, as foreseen.

Moreover, the system performance towards gas mixtures was tested. The tests consisted of keeping the $\mathrm{NH}_{3}$ concentration fixed while variating the $\mathrm{NO}_{2}$ concentration (250, 500 , and $750 \mathrm{ppb}$ ) using the gas cycles and baseline recovery time exposed in Section 2.3. This set was repeated twice, working at two different $\mathrm{NH}_{3}$ concentrations (4 and $15 \mathrm{ppm}$ ). The PCA scores from the results of these tests allow discrimination between observations when the presence of single gases is detected (just $\mathrm{NO}_{2}$, just $\mathrm{NH}_{3}$ ) and when a mixture of these gases is present. PCR models developed for single gas concentration quantification were not accurate to quantify gas mixtures. Further study is needed to quantify the gas concentration in presence of gas mixtures using multivariate analysis methods.

The methods implemented here suppose a reduction in the time needed to identify the gas concentration in comparison to the process presented by Gonzalez et al. in [31], and even an improvement of the results obtained in [56]. Also, the combined use of low temperature and light modulation allows a power consumption reduction of about $90 \%$ as compared to the traditional thermal activation of MOX sensors (using the same substrates as in the present work), where operating temperatures of $100-500{ }^{\circ} \mathrm{C}$ are used. Moreover, sensors were operated under pulsed light modulation for over one month and the morphology of nanomaterials remained unchanged and so was their response to the species tested. In addition, the cost of visible-light LEDs is 10 times lower than that of UV light LEDs used here, and 250 times lower than the cost of the UV light LEDs used in [56].

\section{Conclusions}

In this paper, $\mathrm{WO}_{3}$ and $\mathrm{SrTiO}_{3} @ \mathrm{WO}_{3}$ (n-type) and $\mathrm{WS}_{2}$ (p-type) sensors were synthesized and characterized. The combination of UV or visible pulsed light modulation with low temperature was employed to modulate the resistance of sensors in a background of oxidizing or reducing species. The use of pulsed light modulation, FFT analysis, PCA, and linear regression techniques for building predictive models to identify and quantify gases has been implemented. PCA scores enable the discrimination between the two different target gases $\left(\mathrm{NO}_{2}\right.$ and $\left.\mathrm{NH}_{3}\right)$. Prediction models with up to 0.98 of $\mathrm{R}$-square value and RMSE value lower than $10 \%$ over the total concentration range measured were obtained. The sensing layer activation mechanism applied enables a power consumption reduction of more than $90 \%$ in comparison to the one of traditional high temperature operated MOX non-MEMS sensors. Moreover, the sensor signal period used to quantify target gases was reduced with respect to previously published results, thus shortening the time needed for quantification. Using visible light $(410 \mathrm{~nm})$ led to better results than using UV light $(365 \mathrm{~nm})$. On the other hand, it was demonstrated that p-type sensors achieved better performance to quantify reducing gases, while it was confirmed that n-type sensors exhibit higher efficacy to quantify oxidizing gases. The loading of $\mathrm{SrTiO}_{3}$ nanoparticles to $\mathrm{WO}_{3}$ led to better results both in the discrimination between gases and the quantification of oxidizing species. The methodology presented in this work opens an opportunity to use non-MEMS MOX sensors in real gas sensing applications, since reducing and oxidizing gas concentrations can be accurately quantified using a short period of sensor signal and thus, saving a considerable amount of power.

Supplementary Materials: The following are available online at https:/ / www.mdpi.com/article/ 10.3390/s21113736/s1, Figure S1: Experimental setup used to carry out gas sensing measurements; Figure S2: EDX analysis spectra from (a) $\mathrm{WO}_{3}$ pristine sensor and (b) $\mathrm{WS}_{2}$ sensor; Figure S3: XRD pattern from (a) $\mathrm{WO}_{3}$ pristine sensor and (b) $\mathrm{WS}_{2}$ sensor; Figure S4: (a) $\mathrm{SrTiO}_{3} @ \mathrm{WO}_{3}$ sample XPS survey spectrum, (b) XPS spectrum recorded in the $\mathrm{W} 4 \mathrm{f}$ binding energy region; Figure S5: ToF-SIMS analysis spectrum from the $\mathrm{SrTiO}_{3} @ \mathrm{WO}_{3}$ sensor; Figure S6: (a) XPS spectrum recorded in the S 2p binding energy region, (b) XPS spectrum recorded in the W $4 \mathrm{f}$ binding energy region; Figure S7: Sensors' response working under standard heating activation at $150{ }^{\circ} \mathrm{C}$; Figure S8: PCA biplot analysis for the FFT component discrimination for the target gas identification and $\mathrm{NO}_{2}$ concentration 
determination; Figure S9: PCA biplot analysis for the FFT component discrimination for the identification of different $\mathrm{NH}_{3}$ concentrations; Figure S10: PCR calibration model and cross-validation for the $\mathrm{SrTiO}_{3}$ doped $\mathrm{WO}_{3}$ sensor towards $\mathrm{NO}_{2}$ concentrations under (a) visible light modulation and (b) UV light modulation; Figure S11: PCR calibration model for the (a) $\mathrm{WS}_{2}$ sensor towards $\mathrm{NO}_{2}$ concentrations, (b) $\mathrm{SrTiO}_{3} @ \mathrm{WO}_{3}$ sensor towards $\mathrm{NH}_{3}$ concentrations and (c) $\mathrm{WO}_{3}$ sensor towards $\mathrm{NH}_{3}$ concentrations.

Author Contributions: E.G. experiments, interpretation of results, writing original draft preparation, data curation; J.C.-C. experiements (material synthesis); A.A., experiements (material synthesis); A.R. supervision, manuscript revision and edition; X.V. conceptualization, supervision, fund acquisition, manuscript revision and edition; S.A. experiments, interpretation (XPS); D.C. experiments, interpretation (ToF-SIMS); C.B. supervision (XPS ToF-SIMS), manuscript revision and edition; E.L. fund acquisition and manuscript revision and edition. All authors have read and agreed to the published version of the manuscript.

Funding: This project has received funding from the European Union's Horizon 2020 research and innovation program under the Marie Sklodowska-Curie grant agreement 823895. This work was supported in part by MICINN and FEDER via grants no. RTI2018-101580-B-I00, by AGAUR under grant. 2017SGR418. E.G. gratefully acknowledges a predoctoral fellowship from AGAUR, supported by the European Social Fund. E.L. is supported by the Catalan Institution for Research and Advanced Studies via the 2018 Edition of the ICREA Academia Award. CB thanks the Belgian Fund for Scientific Research under the FRFC contract CDR J001019. J.C.-C. gratefully acknowledges a postdoctoral ICREA Academia fellowship.

Data Availability Statement: Raw data are available from authors upon request.

Acknowledgments: We are grateful to the MINOS group technician Xavier Blanch for assembling the electronic components of the light activation control system. CB is a Research Associate of the National Funds for Scientific Research (FNRS, Belgium).

Conflicts of Interest: The authors declare no conflict of interest.

\section{References}

1. World Health Organization. Air Pollution. Available online: https://www.who.int/health-topics/air-pollution\#tab=tab_1 (accessed on 14 August 2020).

2. CDC-NIOSH Pocket Guide to Chemical Hazards-Nitrogen Dioxide. Available online: https://www.cdc.gov/niosh/npg/ npgd0454.html (accessed on 2 February 2021).

3. CDC-Immediately Dangerous to Life or Health Concentrations (IDLH): Ammonia-NIOSH Publications and Products. Available online: https:/ / www.cdc.gov/niosh/idlh/7664417.html (accessed on 2 February 2021).

4. Berner, T.; Cogliano, V.; Fritz, J.; Gehlhaus, M.; Jones, S.; Stanek, J.; Strong, J. Toxicological Review of Ammonia Noncancer Inhalation [CASRN 7664-41-7]. 2016. Available online: https:/ /iris.epa.gov/static/pdfs/0422tr.pdf (accessed on 28 October 2020).

5. Bevc, S.; Mohorko, E.; Kolar, M.; Brglez, P.; Holobar, A.; Kniepeiss, D.; Podbregar, M.; Piko, N.; Hojs, N.; Knehtl, M.; et al. Measurement of breath ammonia for detection of patients with chronic kidney disease. Clin. Nephrol. 2017, 88, 14-17. [CrossRef]

6. Ahlawat, A.; Mishra, S.; Gumber, S.; Goel, V.; Sharma, C.; Wiedensohler, A. Performance evaluation of light weight gas sensor system suitable for airborne applications against co-location gas analysers over Delhi. Sci. Total Environ. 2019, 697, 134016. [CrossRef] [PubMed]

7. Xiong, B.; Mahoney, E.; Lo, J.F.; Fang, Q. A Frequency-domain optofluidic dissolved oxygen sensor with total internal reflection design for in situ monitoring. IEEE J. Sel. Top. Quantum Electron. 2020, 1. [CrossRef]

8. Maricar, S.M.M.; Sastikumar, D.; Vanga, P.R.; Ashok, M. Fiber optic gas sensor response of hydrothermally synthesized nanocrystalline bismuth tungstate to methanol. Mater. Lett. 2021, 288, 129337. [CrossRef]

9. Liu, W.; Gu, D.; Li, X. Ultrasensitive $\mathrm{NO}_{2}$ Detection Utilizing Mesoporous ZnSe/ZnO Heterojunction-Based Chemiresistive-Type Sensors. ACS Appl. Mater. Interfaces 2019, 11, 29029-29040. [CrossRef]

10. Jha, R.K.; Singh, V.; Sinha, J.; Avasthi, S.; Bhat, N. CVD Grown Cuprous Oxide Thin Film Based High Performance Chemiresistive Ammonia Gas Sensors. IEEE Sens. J. 2019, 19, 11759-11766. [CrossRef]

11. Pandey, P.A.; Wilson, N.; Covington, J.A. Pd-doped reduced graphene oxide sensing films for H2 detection. Sens. Actuators $B$ Chem. 2013, 183, 478-487. [CrossRef]

12. Tao, Y.; Gao, Q.; Di, J.; Wu, X. Gas Sensors Based on $\alpha-\mathrm{Fe}_{2} \mathrm{O}_{3}$ Nanorods, Nanotubes and Nanocubes. J. Nanosci. Nanotechnol. 2013, 13, 5654-5660. [CrossRef]

13. Larin, A.; Womble, P.C.; Dobrokhotov, V. Hybrid $\mathrm{SnO}_{2} / \mathrm{TiO}_{2}$ Nanocomposites for Selective Detection of Ultra-Low Hydrogen Sulfide Concentrations in Complex Backgrounds. Sensors 2016, 16, 1373. [CrossRef] 
14. Wu, T.-C.; Dai, J.; Hu, G.; Yu, W.-B.; Ogbeide, O.; De Luca, A.; Huang, X.; Su, B.-L.; Li, Y.; Udrea, F.; et al. Machine-intelligent inkjet-printed $\alpha-\mathrm{Fe}_{2} \mathrm{O}_{3} / \mathrm{rGO}$ towards $\mathrm{NO}_{2}$ quantification in ambient humidity. Sens. Actuators B Chem. 2020, 321, 128446. [CrossRef]

15. Qamar, M.; Adam, A.; Azad, A.-M.; Kim, Y.-W. Benzyl Alcohol-Mediated Versatile Method to Fabricate Nonstoichiometric Metal Oxide Nanostructures. ACS Appl. Mater. Interfaces 2017, 9, 40573-40579. [CrossRef]

16. Ahmad, A.; Voves, J. Selective sensing of volatile organic compounds via a temperature modulation of metal oxide gas sensors with principal component analysis. In Proceedings of the 11th International Conference on Nanomaterials-Research \& Application, Brno, Czech Republic, 16-18 October 2019.

17. Ponzoni, A.; Comini, E.; Concina, I.; Ferroni, M.; Falasconi, M.; Gobbi, E.; Sberveglieri, V.; Sberveglieri, G. Nanostructured Metal Oxide Gas Sensors, a Survey of Applications Carried out at SENSOR Lab, Brescia (Italy) in the Security and Food Quality Fields. Sensors 2012, 12, 17023-17045. [CrossRef] [PubMed]

18. Tisch, U.; Haick, H. Chemical sensors for breath gas analysis: The latest developments at the Breath Analysis Summit 2013. J. Breath Res. 2014, 8, 027103. [CrossRef]

19. Nunes, D.; Pimentel, A.; Gonçalves, A.; Pereira, S.; Branquinho, R.; Barquinha, P.; Fortunato, E.; Martins, R. Metal oxide nanostructures for sensor applications. Semicond. Sci. Technol. 2019, 34, 043001. [CrossRef]

20. Fazio, E.; Spadaro, S.; Corsaro, C.; Neri, G.; Leonardi, S.; Neri, F.; Lavanya, N.; Sekar, C.; Donato, N.; Neri, G. Metal-Oxide Based Nanomaterials: Synthesis, Characterization and Their Applications in Electrical and Electrochemical Sensors. Sensors 2021, 21, 2494. [CrossRef]

21. Bhati, V.S.; Hojamberdiev, M.; Kumar, M. Enhanced sensing performance of ZnO nanostructures-based gas sensors: A review. Energy Rep. 2020, 6, 46-62. [CrossRef]

22. Liu, X.; Cheng, S.; Liu, H.; Hu, S.; Zhang, D.; Ning, H. A Survey on Gas Sensing Technology. Sensors 2012, 12, 9635-9665. [CrossRef]

23. Zhou, C.; Yang, W.; Zhu, H. Mechanism of charge transfer and its impacts on Fermi-level pinning for gas molecules adsorbed on monolayer $\mathrm{WS}_{2}$. J. Chem. Phys. 2015, 142, 214704. [CrossRef] [PubMed]

24. Meng, F.; Zhu, T.; Yuan, Z.; Qin, W.; Gao, H.; Zhang, H. Investigation of Mixed-Phase WS2 Nanomaterials for Ammonia Gas Sensing. IEEE Sens. J. 2021, 21, 7268-7274. [CrossRef]

25. Zappa, D.; Galstyan, V.; Kaur, N.; Arachchige, H.M.M.; Sisman, O.; Comini, E. "Metal oxide -based heterostructures for gas sensors"-A review. Anal. Chim. Acta 2018, 1039, 1-23. [CrossRef] [PubMed]

26. He, A.; Tang, Z. A Novel Gas Identification Method Based on Gabor Spectrogram Using Self-adapted Temperature Modulated Gas Sensors. In Proceedings of the 2019 International Conference on Sensing, Diagnostics, Prognostics, and Control (SDPC), Beijing, China, 15-17 August 2019; pp. 714-717.

27. Vallejos, S.; Stoycheva, T.; Umek, P.; Navio, C.; Snyders, R.; Bittencourt, C.; Llobet, E.; Blackman, C.; Moniz, S.; Correig, X. Au nanoparticle-functionalised WO3nanoneedles and their application in high sensitivity gas sensor devices. Chem. Commun. 2011, 47, 565-567. [CrossRef] [PubMed]

28. Karaduman, I.; Yıldız, D.E.; Sincar, M.M.; Acar, S. UV light activated gas sensor for $\mathrm{NO}_{2}$ detection. Mater. Sci. Semicond. Process. 2014, 28, 43-47. [CrossRef]

29. Ilin, A.; Martyshov, M.; Forsh, E.; Forsh, P.; Rumyantseva, M.; Abakumov, A.; Gaskov, A.; Kashkarov, P. UV effect on $\mathrm{NO}_{2}$ sensing properties of nanocrystalline $\mathrm{In}_{2} \mathrm{O}_{3}$. Sens. Actuators B Chem. 2016, 231, 491-496. [CrossRef]

30. Chinh, N.D.; Kim, C.; Kim, D. UV-light-activated $\mathrm{H}_{2} \mathrm{~S}$ gas sensing by a $\mathrm{TiO}_{2}$ nanoparticulate thin film at room temperature. J. Alloy. Compd. 2019, 778, 247-255. [CrossRef]

31. Gonzalez, O.; Welearegay, T.; Llobet, E.; Vilanova, X. Pulsed UV Light Activated Gas Sensing in Tungsten Oxide Nanowires. Procedia Eng. 2016, 168, 351-354. [CrossRef]

32. Comini, E.; Faglia, G.; Sberveglieri, G. UV light activation of tin oxide thin films for $\mathrm{NO}_{2}$ sensing at low temperatures. Sens. Actuators B Chem. 2001, 78, 73-77. [CrossRef]

33. Huang, J.; Du, Y.; Wang, Q.; Zhang, H.; Geng, Y.; Li, X.; Tian, X. UV-Enhanced Ethanol Sensing Properties of RF MagnetronSputtered ZnO Film. Sensors 2017, 18, 50. [CrossRef]

34. Espid, E.; Taghipour, F. UV-LED Photo-activated Chemical Gas Sensors: A Review. Crit. Rev. Solid State Mater. Sci. 2017, 42, 416-432. [CrossRef]

35. Trocino, S.; Frontera, P.; Donato, A.; Busacca, C.; Scarpino, L.; Antonucci, P.; Neri, G. Gas sensing properties under UV radiation of In2O3 nanostructures processed by electrospinning. Mater. Chem. Phys. 2014, 147, 35-41. [CrossRef]

36. Gu, D.; Li, X.; Wang, H.; Li, M.; Xi, Y.; Chen, Y.; Wang, J.; Rumyntseva, M.N.; Gaskov, A.M. Light enhanced VOCs sensing of WS2 microflakes based chemiresistive sensors powered by triboelectronic nangenerators. Sens. Actuators B Chem. 2018, 256, 992-1000. [CrossRef]

37. Chen, H.; Zhang, M.; Fu, X.; Fusco, Z.; Bo, R.; Xing, B.; Nguyen, H.T.; Barugkin, C.; Zheng, J.; Lau, C.F.J.; et al. Light-activated inorganic CsPbBr2I perovskite for room-temperature self-powered chemical sensing. Phys. Chem. Chem. Phys. 2019, 21, 24187-24193. [CrossRef]

38. Gu, D.; Wang, X.; Liu, W.; Li, X.; Lin, S.; Wang, J.; Rumyantseva, M.N.; Gaskov, A.M.; Akbar, S.A. Visible-light activated room temperature NO2 sensing of SnS2 nanosheets based chemiresistive sensors. Sens. Actuators B Chem. 2020, 305, 127455. [CrossRef]

39. Chizhov, A.; Rumyantseva, M.; Drozdov, K.; Krylov, I.; Batuk, M.; Hadermann, J.; Filatova, D.; Khmelevsky, N.; Kozlovsky, V.; Maltseva, L.; et al. Photoresistive gas sensor based on nanocrystalline $\mathrm{ZnO}$ sensitized with colloidal perovskite $\mathrm{CsPbBr3}$ nanocrystals. Sens. Actuators B Chem. 2021, 329, 129035. [CrossRef] 
40. Gonzalez, O.; Roso, S.; Vilanova, X.; Llobet, E. Enhanced detection of nitrogen dioxide via combined heating and pulsed UV operation of indium oxide nano-octahedra. Beilstein J. Nanotechnol. 2016, 7, 1507-1518. [CrossRef]

41. Gonzalez, O.; Welearegay, T.G.; Vilanova, X.; Llobet, E. Using the Transient Response of $\mathrm{WO}_{3}$ Nanoneedles under Pulsed UV Light in the Detection of $\mathrm{NH}_{3}$ and $\mathrm{NO}_{2}$. Sensors 2018, 18, 1346. [CrossRef] [PubMed]

42. Su, P.-G.; Yu, J.-H.; Chen, I.-C.; Syu, H.-C.; Chiu, S.-W.; Chou, T.-I. Detection of ppb-level $\mathrm{NO}_{2}$ gas using a portable gas-sensing system with a $\mathrm{Fe}_{2} \mathrm{O}_{3} / \mathrm{MWCNTs} / \mathrm{WO}_{3}$ sensor using a pulsed-UV-LED. Anal. Methods 2019, 11, 973-979. [CrossRef]

43. Szulczyński, B.; Namieśnik, J.; Gębicki, J. Determination of Odour Interactions of Three-Component Gas Mixtures Using an Electronic Nose. Sensors 2017, 17, 2380. [CrossRef] [PubMed]

44. Burgués, J.; Marco, S. Low Power Operation of Temperature-Modulated Metal Oxide Semiconductor Gas Sensors. Sensors 2018, 18, 339. [CrossRef]

45. Burgués, J.; Marco, S. Multivariate estimation of the limit of detection by orthogonal partial least squares in temperaturemodulated MOX sensors. Anal. Chim. Acta 2018, 1019, 49-64. [CrossRef] [PubMed]

46. Skotadis, E.; Kanaris, A.; Aslanidis, E.; Michalis, P.; Kalatzis, N.; Chatzipapadopoulos, F.; Marianos, N.; Tsoukalas, D. A sensing approach for automated and real-time pesticide detection in the scope of smart-farming. Comput. Electron. Agric. 2020, 178, 105759. [CrossRef]

47. Sett, A.; Rana, T.; Roy, R.; Saha, T.; Bhattacharyya, T.K. Selective detection of multiple VOCs employing zinc oxide nanorods and principle component. In Proceedings of the 2020 4th International Conference on Electronics, Materials Engineering \& Nano-Technology (IEMENTech), Kolkata, India, 2-4 October 2020.

48. Deng, F.; Chen, W.; Wang, J.; Wei, Z. Fabrication of a sensor array based on quartz crystal microbalance and the application in egg shelf life evaluation. Sens. Actuators B Chem. 2018, 265, 394-402. [CrossRef]

49. Palacín, J.; Martínez, D.; Clotet, E.; Pallejà, T.; Burgués, J.; Fonollosa, J.; Pardo, A.; Marco, S. Application of an Array of Metal-Oxide Semiconductor Gas Sensors in an Assistant Personal Robot for Early Gas Leak Detection. Sensors 2019, $19,1957$. [CrossRef] [PubMed]

50. Lee, J.; Jung, Y.; Sung, S.-H.; Lee, G.-H.; Kim, J.; Seong, J.; Shim, Y.-S.; Jun, S.C.; Jeon, S. High-performance gas sensor array for indoor air quality monitoring: The role of Au nanoparticles on $\mathrm{WO}_{3}, \mathrm{SnO}_{2}$, and NiO-based gas sensors. J. Mater. Chem. A 2021, 9 , 1159-1167. [CrossRef]

51. Khan, A.H.; Thomson, B.; Debnath, R.; Motayed, A.; Rao, M.V. Nanowire-Based Sensor Array for Detection of Cross-Sensitive Gases Using PCA and Machine Learning Algorithms. IEEE Sens. J. 2020, 20, 6020-6028. [CrossRef]

52. Chu, J.; Rong, M.; Li, W.; Yang, X.; Yu, H.; Wang, D.; Fan, C.; Yang, A.; Li, Y.; Wang, X. Quantitative Detection of Mixed Gases by Sensor Array Using C-Means Clustering and Artificial Neural Network. In Proceedings of the IECON 2019-45th Annual Conference of the IEEE Industrial Electronics Society, Lisbon, Portugal, 14-17 September 2019; pp. 6748-6751.

53. Freddi, S.; Drera, G.; Pagliara, S.; Goldoni, A.; Sangaletti, L. Enhanced selectivity of target gas molecules through a minimal array of gas sensors based on nanoparticle-decorated SWCNTs. Analyst 2019, 144, 4100-4110. [CrossRef]

54. Ghosh, A.; Maity, A.; Banerjee, R.; Majumder, S. Volatile organic compound sensing using copper oxide thin films: Addressing the cross sensitivity issue. J. Alloy. Compd. 2017, 692, 108-118. [CrossRef]

55. Wozniak, L.; Kalinowski, P.; Jasinski, G.; Jasinski, P. FFT analysis of temperature modulated semiconductor gas sensor response for the prediction of ammonia concentration under humidity interference. Microelectron. Reliab. 2018, 84, 163-169. [CrossRef]

56. Gonzalez, E.; Llobet, E.; Romero, A.; Vilanova, X. A New Approach to $\mathrm{NO}_{2}$ Gas Sensing Based on Pulsed UV Light and FFT Analysis Using MOX Sensors. IEEE Sens. J. 2019, 20, 397-404. [CrossRef]

57. Annanouch, F.E.; Haddi, Z.; Vallejos, S.; Umek, P.; Guttmann, P.; Bittencourt, C.; Llobet, E. Aerosol-Assisted CVD-Grown WO 3 Nanoneedles Decorated with Copper Oxide Nanoparticles for the Selective and Humidity-Resilient Detection of $\mathrm{H}_{2} \mathrm{~S}$. ACS Appl. Mater. Interfaces 2015, 7, 6842-6851. [CrossRef]

58. Qi, J.; Chen, K.; Xing, Y.; Fan, H.; Zhao, H.; Yang, J.; Li, L.; Yan, B.; Zhou, J.; Guo, L.; et al. Application of 3D hierarchical monoclinictype structural Sb-doped $\mathrm{WO}_{3}$ towards $\mathrm{NO}_{2}$ gas detection at low temperature. Nanoscale 2018, 10, 7440-7450. [CrossRef]

59. Wu, Y.; Wei, Y.; Guo, Q.; Xu, H.; Gu, L.; Huang, F.; Luo, D.; Huang, Y.; Fan, L.; Wu, J. Solvothermal fabrication of $\mathrm{La}^{-\mathrm{WO}_{3} / \mathrm{SrTiO}_{3}}$ heterojunction with high photocatalytic performance under visible light irradiation. Sol. Energy Mater. Sol. Cells 2018, 176, 230-238. [CrossRef]

60. Braga, D.; Lezama, I.G.; Berger, H.; Morpurgo, A.F. Quantitative Determination of the Band Gap of WS 2 with Ambipolar Ionic Liquid-Gated Transistors. Nano Lett. 2012, 12, 5218-5223. [CrossRef]

61. Tanabe, I.; Gomez, M.; Coley, W.C.; Le, D.; Echeverria, E.M.; Stecklein, G.; Kandyba, V.; Balijepalli, S.K.; Klee, V.; Nguyen, A.E.; et al. Band structure characterization of WS2 grown by chemical vapor deposition. Appl. Phys. Lett. 2016, 108, 252103. [CrossRef]

62. Díaz-Reyes, J.; Castillo-Ojeda, R.; Galván-Arellano, M.; Zaca-Moran, O. Characterization of $\mathrm{WO}_{3}$ Thin Films Grown on Silicon by HFMOD. Adv. Condens. Matter Phys. 2013, 2013, 591787. [CrossRef]

63. Xu, L.; Yin, M.-L.; Liu, S. (Frank) Agx@WO 3 core-shell nanostructure for LSP enhanced chemical sensors. Sci. Rep. 2014, 4, 6745. [CrossRef]

64. Liu, F.; Chen, X.; Xia, Q.; Tian, L.; Chen, X. Ultrathin tungsten oxide nanowires: Oleylamine assisted nonhydrolytic growth, oxygen vacancies and good photocatalytic properties. RSC Adv. 2015, 5, 77423-77428. [CrossRef]

65. Alagh, A.; Annanouch, F.E.; Umek, P.; Bittencourt, C.; Sierra-Castillo, A.; Haye, E.; Colomer, J.F.; Llobet, E. CVD growth of selfassembled 2D and $1 \mathrm{D} \mathrm{WS} 2$ nanomaterials for the ultrasensitive detection of $\mathrm{NO}_{2}$. Sens. Actuators B Chem. 2021, 326, 128813. [CrossRef] 